\title{
Maize/Soybean Relay Strip Intercropping Reduces the Occurrence of Fusarium Root Rot and Changes the Diversity of the Pathogenic Fusarium Species
}

\author{
Xiaoli Chang ${ }^{1,2,+}$, Li Yan $^{2,+}$, Muhammd Naeem ${ }^{2,+}{ }^{-}$, Muhammad Ibrahim Khaskheli $^{3}{ }^{(0)}$, \\ Hao Zhang ${ }^{1}$, Guoshu Gong ${ }^{2}$, Min Zhang ${ }^{2}$, Chun Song ${ }^{2}{ }^{(D}$, Wenyu Yang ${ }^{2}$, Taiguo Liu ${ }^{1,4}$ and \\ Wanquan Chen ${ }^{1,4, *}$ \\ 1 State Key Laboratory for Biology of Plant Diseases and Insect Pests, Institute of Plant Protection, \\ Chinese Academy of Agricultural Sciences, Beijing 100193, China; xl_changkit@126.com (X.C.); \\ zhanghao@caas.cn (H.Z.); liutaiguo@caas.cn (T.L.) \\ 2 College of Agronomy \& Sichuan Engineering Research Center for Crop Strip Intercropping system, \\ Sichuan Agricultural University, Chengdu 611130, Sichuan Province, China; mirror_dis@126.com (L.Y.); \\ muhammdnaeem201@gmail.com (M.N.); guoshugong@126.com (G.G.); yalanmin@126.com (M.Z.); \\ songchun@sicau.edu.cn (C.S.); mssiyangwy@sicau.edu.cn (W.Y.) \\ 3 Department of Plant Protection, Faculty of Crop Protection, Sindh Agriculture University, \\ Tandojam 70060, Pakistan; mikhaskheli@sau.edu.pk \\ 4 National Agricultural Experimental Station for Plant Protection, Ministry of Agriculture and Rural Affairs, \\ Tianshui 741000, Gansu Province, China \\ * Correspondence: wqchen@ippcaas.cn; Tel.: +86-10-62815618; Fax: +86-10-62895365 \\ $\dagger$ These authors contributed equally to this work.
}

Received: 6 February 2020; Accepted: 10 March 2020; Published: 13 March 2020

\begin{abstract}
Fusarium species are the most detrimental pathogens of soybean root rot worldwide, causing large loss in soybean production. Maize/soybean relay strip intercropping has significant advantages on the increase of crop yields and efficient use of agricultural resources, but its effects on the occurrence and pathogen population of soybean root rot are rarely known. In this study, root rot was investigated in the fields of the continuous maize/soybean strip relay intercropping and soybean monoculture. Fusarium species were isolated from diseased soybean roots and identified based on sequence analysis of translation elongation factor $1 \alpha(E F-1 \alpha)$ and RNA polymerase II second largest subunit (RPB2), and the diversity and pathogenicity of these species were also analyzed. Our results showed that intercropping significantly decreased soybean root rot over monoculture. A more diverse Fusarium population including Fusarium solani species complex (FSSC), F. incarnatum-equiseti species complex (FIESC), F. oxysporum, F. fujikuroi, F. proliferatum and F. verticillioides, F. graminearum and $F$. asiaticum was identified from intercropping while FSSC, FIESC, F. oxysporum, F. commune, $F$. asiaticum and F. meridionale were found from monoculture. All Fusarium species caused soybean root infection but exhibited distinct aggressiveness. The most aggressive F. oxysporum was more frequently isolated in monoculture than intercropping. FSSC and FIESC were the dominant species complex and differed in their aggressiveness. Additionally, F. fujikuroi, F. proliferatum and F. verticillioides were specifically identified from intercropping with weak or middle aggressiveness. Except for $F$. graminearum, F. meridionale and F. asiaticum were firstly reported to cause soybean root rot in China. This study indicates maize/soybean relay strip intercropping can reduce soybean root rot, change the diversity and aggressiveness of Fusarium species, which provides an important reference for effective management of this disease.
\end{abstract}

Keywords: Maize/soybean rely strip intercropping; soybean root rot; Fusarium species; population diversity; pathogenicity 


\section{Introduction}

Fusarium root rot has been considered as one of the most destructive soil-borne diseases in almost all soybean growing areas worldwide and causes a drastic reduction in the optimum yield and ultimately the substantial economic losses [1]. So far, it has reported that more than 20 Fusarium species are pathogenic to soybean [2-8]. However, the diversity and pathogenicity of these Fusarium species can be often affected by climate factors, soybean cultivars, cropping pattern and other agricultural practices. Although high disease-resistant cultivars of soybean are still lacking [9,10], several other disease management practices including chemical fungicides [11], biological control agents [12,13], crop rotation/intercropping [14,15] and tilling [16], have been commonly adopted to control the Fusarium root rot.

Intercropping has been well known as one kind of the sustainable agricultural cropping patterns around the world [17-19]. Many studies have demonstrated that intercropping not only has obvious advantages on the increase of crop productivity [20-22] and efficient exploration of agricultural resources [23,24] when compared with crop monoculture, but simultaneously it can also suppress the soil-borne diseases [17]. Recent research indicated that intercropping reduced the occurrence of Phytophthora blight of pepper in maize/pepper intercropping [25], suppressed the incidence of Fusarium wilt of watermelon in rice/watermelon intercropping [26] and wheat/maize intercropping [15,27], and soybean red crown rot caused by Cylindrocladium parasiticum in maize/soybean intercropping [14]. Moreover, intercropping can affect soil microbial communities, reduce the attacks of pathogens and inhibit soil-borne diseases $[14,17,25,28,29]$. Nowadays, several intercropping patterns have been widely practiced in Asia, Latin America, Africa and other European countries regarding to local crop species and diverse climate conditions $[18,19,30]$. However, there is still very limited knowledge on the effects and underlying mechanisms of distinct intercropping patterns on controlling soil-borne diseases.

Recently, a maize/soybean relay strip intercropping, which is characterized by two rows of maize intercropped with two-to-four rows of soybean, has been developed in Southwest China aiming to efficiently exploit the locally limited solar-thermal and soil resources [19,31]. A range of recent studies have demonstrated that in contrast to monoculture, this creative intercropping increases crop yield [32], enhances land equivalent ratio (LER) [31], improves soil quality [33,34], suppresses field weeds [35], disease and pests [36]. Currently, the planting area of the maize/soybean relay strip intercropping system has been widely increasing in Southwest China and has also been used in the other single-season cropping areas [19]. Nevertheless, very few investigations are conducted to determine the influences of this system on soil-borne diseases such as soybean root rot.

The objectives of the present study were to investigate the incidence of soybean root rot and compare the diversity and pathogenicity of Fusarium species in soybean monoculture and maize/soybean relay strip intercropping. Our study will provide some references for better understanding the influence of the intercropping systems on the soil-borne diseases and the pathogen population, and this may be helpful to formulate the agricultural practices for sustainable disease management.

\section{Results}

\subsection{Occurrence of Soybean Root Rot in Soybean Monoculture and Maize/Soybean Relay Strip Intercropping}

In this study, we investigated the occurrence of soybean root rot in soybean monoculture and intercropping from 2015 to 2018. We found that disease incidence (DI) of soybean root rot was steady from 2015 to 2017 in both cropping patterns, whereas a significant increase $(p<0.05)$ was observed in 2018 when the DI reached up to $61.02 \%$ in monoculture and $24.28 \%$ in intercropping, respectively (Figure 1A). In addition, the DI in monoculture was always significantly higher $(p<0.05)$ than that in intercropping each year (Figure 1A). Similarly, the disease severity index (DSI) of root rot gradually increased as the planting continued over year, and it rose up to 17.88 in monoculture in 2018 which was almost 2-fold higher than that in intercropping (Figure 1B). Thus, the continuous planting increased 
soybean root rot in both planting patterns, but maize/soybean relay strip intercropping was able to decrease the DI and DSI of soybean root rot as compared to monoculture.
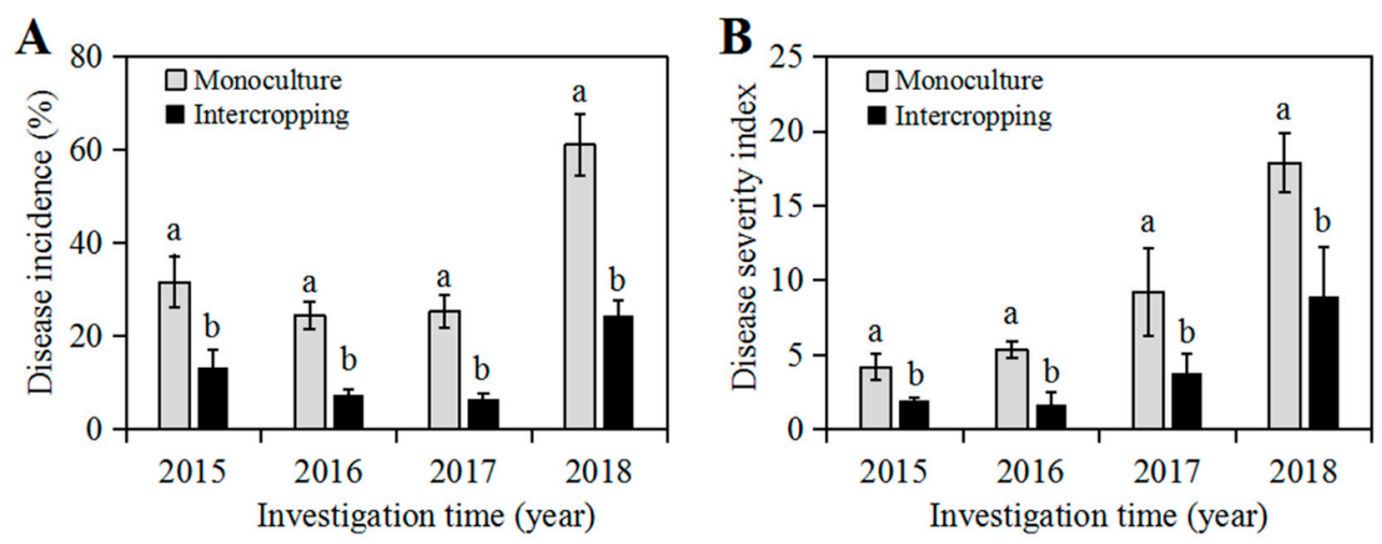

Figure 1. Disease incidence and disease severity index of soybean root rot in soybean monoculture and maize/soybean intercropping during 2015-2018. A. Disease incidence of soybean root rot; B. Disease severity index. Error bars indicate the standard error of the mean of three independent plots, and each is composed of 210 soybean plants. Within each year, bars with different letters are significantly different according to Duncan's test $(p<0.05)$.

\subsection{Identification of Fusarium Species from Soybean Monoculture and Maize/Soybean Relay Strip Intercropping}

After isolation and purification, a total of 37 isolates were obtained from diseased soybean roots in monoculture when compared with 36 isolates in intercropping (Table 1). Partial sequences of translation elongation factor $1 \alpha(E F-1 \alpha)$ and RNA polymerase II second largest subunit (RPB2) gene were sequenced and blasted against the databases of Fusarium MLST (http://www.wi.knaw.nl/Fusarium/Biolomics.aspx) and FUSARIUM-ID (http://isolate.fusariumdb.org/guide.php) to identify Fusarium species. Our results showed that these isolates had more than $98 \%$ sequence similarity with 10 species or species complex including Fusarium solani species complex (FSSC), Fusarium incarnatum-equiseti species complex (FIESC), F. oxysporum, F. commune, three species (F. fujikuroi, F. proliferatum, F. verticillioides) belonging to Fusarium fujikuroi species complex (FFSC) and three species (F. graminearum, F. asiaticum and F. meridionale) in the Fusarium graminearum species complex (FGSC) (Table 1).

Table 1. Information of Fusarium isolates obtained from soybean monoculture and intercropping and GenBank accession numbers of EF-1 $\alpha$ and RPB2.

\begin{tabular}{|c|c|c|c|c|c|}
\hline \multirow{2}{*}{ Isolate Code } & \multirow{2}{*}{$\begin{array}{l}\text { Planting } \\
\text { Pattern }\end{array}$} & \multicolumn{2}{|c|}{ GenBank Accession Number } & \multirow{2}{*}{ Fusarium Species ${ }^{\text {a }}$} & \multirow{2}{*}{ Fusarium Species Complex } \\
\hline & & $E F-1 \alpha$ & $R P B 2$ & & \\
\hline $\mathrm{A} 1 \mathrm{~s} 4$ & Intercropping & MK560306 & MN892318 & F. graminearum & $\begin{array}{l}\text { Fusarium graminearum species } \\
\text { complex, FGSC [37] }\end{array}$ \\
\hline A1s5 & Intercropping & MK560320 & MN892327 & FIESC & $\begin{array}{l}\text { Fusarium incarnatum-equiseti } \\
\text { species complex, FIESC }[38,39]\end{array}$ \\
\hline A1r3 & Intercropping & MK560319 & MN892328 & FIESC & FIESC \\
\hline A2s 1 & Intercropping & MK560321 & MN892326 & FIESC & FIESC \\
\hline $\mathrm{A} 2 \mathrm{~s} 3$ & Intercropping & MK560322 & MN892325 & FIESC & FIESC \\
\hline $\mathrm{A} 2 \mathrm{~s} 4$ & Intercropping & MK560307 & MN892317 & F. graminearum & FGSC \\
\hline $\mathrm{A} 2 \mathrm{r} 1$ & Intercropping & MK560280 & MN892289 & FSSC & $\begin{array}{l}\text { Fusarium solani species } \\
\text { complex, FSSC [40] }\end{array}$ \\
\hline A3s1 & Intercropping & MK560335 & MN892344 & F. asiaticum & FGSC \\
\hline A3s3 & Intercropping & MN892351 & MN892338 & FSSC & FSSC \\
\hline $\mathrm{A} 4 \mathrm{~s} 1$ & Intercropping & MK560308 & MN892321 & F. fujikuroi & $\begin{array}{l}\text { Fusarium fujikuroi species } \\
\text { complex, FFSC [41] }\end{array}$ \\
\hline $\mathrm{A} 4 \mathrm{~s} 2$ & Intercropping & MK560300 & MN892307 & F. oxysporum & $\begin{array}{l}\text { Fusarium oxysporum species } \\
\text { complex, FOSC }[8,39,40]\end{array}$ \\
\hline $\mathrm{A} 4 \mathrm{~s} 3$ & Intercropping & MK560323 & MN892336 & FIESC & FIESC \\
\hline $\mathrm{A} 4 \mathrm{~s} 4$ & Intercropping & MK560324 & MN892341 & FIESC & FIESC \\
\hline A4s6 & Intercropping & MK560283 & MN892295 & F. solani & FSSC \\
\hline A4r1 & Intercropping & MK560282 & MN892296 & FSSC & FSSC \\
\hline
\end{tabular}


Table 1. Cont.

\begin{tabular}{|c|c|c|c|c|c|}
\hline A5s3 & Intercropping & MK560325 & MN892342 & FIESC & FIESC \\
\hline A5r2 & Intercropping & MK560284 & MN892284 & FSSC & FSSC \\
\hline A6s1 & Intercropping & MK560309 & MN892320 & F. fujikuroi & FFSC \\
\hline A6s2 & Intercropping & MK560326 & MN892324 & FIESC & FIESC \\
\hline A6s3 & Intercropping & MK560301 & MN892306 & F. oxysporum & FOSC \\
\hline A6r2 & Intercropping & MK560285 & MN892294 & F. solani & FSSC \\
\hline A7s2 & Intercropping & MK560261 & MN892281 & F. verticillioides & FFSC \\
\hline A7s3 & Intercropping & MK560327 & MN892323 & FIESC & FIESC \\
\hline A7s5 & Intercropping & MK560262 & MN892280 & F. verticillioides & FFSC \\
\hline A7r1 & Intercropping & MK560302 & MN892305 & F. oxysporum & FOSC \\
\hline A7r2 & Intercropping & MK560286 & MN892293 & F. solani & FSSC \\
\hline A8s3 & Intercropping & MK560263 & MN892279 & F. verticillioides & FFSC \\
\hline A8s4 & Intercropping & MK560328 & MN892343 & FIESC & FIESC \\
\hline A8r2 & Intercropping & MK560288 & MN892291 & FSSC & FSSC \\
\hline A8r4 & Intercropping & MK560287 & MN892292 & F. solani & FSSC \\
\hline A9s1 & Intercropping & MK560310 & MN892319 & F. fujikuroi & FFSC \\
\hline A9s2 & Intercropping & MK560264 & MN892278 & F. verticillioides & FFSC \\
\hline A9s3 & Intercropping & MK560329 & MN892322 & FIESC & FIESC \\
\hline A9s5 & Intercropping & MK560292 & MN892349 & F. proliferatum & FFSC \\
\hline A9s6 & Intercropping & MK560290 & MN892285 & FSSC & FSSC \\
\hline A9r1 & Intercropping & MK560291 & MN892290 & FSSC & FSSC \\
\hline B1r1 & Monoculture & MK560265 & MN892304 & FSSC & FSSC \\
\hline B2s1 & Monoculture & MK560293 & MN892313 & F. oxysporum & FOSC \\
\hline $\mathrm{B} 2 \mathrm{~s} 2$ & Monoculture & MK560303 & MN892316 & F. meridionale & FGSC \\
\hline B2s3 & Monoculture & MK560294 & MN892312 & F. oxysporum & FOSC \\
\hline B2r1 & Monoculture & MK560266 & MN892288 & FSSC & FSSC \\
\hline B2r2 & Monoculture & MK560311 & MN892335 & FIESC & FIESC \\
\hline B2r3 & Monoculture & MK560312 & MN892337 & FIESC & FIESC \\
\hline B2r4 & Monoculture & MK560304 & MN892315 & F. meridionale & FGSC \\
\hline B3s1 & Monoculture & MK560295 & MN892311 & FIESC & FOSC \\
\hline B3s3 & Monoculture & MK560331 & MN892348 & F. asiaticum & FGSC \\
\hline B3s4 & Monoculture & MK560313 & MN892334 & FIESC & FIESC \\
\hline B3s6 & Monoculture & MK560296 & MN892310 & F. oxysporum & FOSC \\
\hline B3r1 & Monoculture & MK560267 & MN892303 & FSSC & FSSC \\
\hline B4s1 & Monoculture & MK560305 & MN892314 & F. meridionale & FGSC \\
\hline B4s3 & Monoculture & MK560314 & MN892333 & FIESC & FIESC \\
\hline B4s4 & Monoculture & MK560315 & MN892339 & FIESC & FIESC \\
\hline B4r1 & Monoculture & MK560268 & MN892283 & FSSC & FSSC \\
\hline B4r2 & Monoculture & MK560269 & MN892286 & FSSC & FSSC \\
\hline B5s1 & Monoculture & MK560270 & MN892302 & FSSC & FSSC \\
\hline B5s2 & Monoculture & MK560297 & MN892309 & F. oxysporum & FOSC \\
\hline B5s4 & Monoculture & MN892352 & MN892332 & FSSC & FSSC \\
\hline B6s1 & Monoculture & MK560272 & MN892301 & FSSC & FSSC \\
\hline B6s2 & Monoculture & MK560316 & MN892331 & FIESC & FIESC \\
\hline B6s3 & Monoculture & MK560332 & MN892347 & F. asiaticum & FGSC \\
\hline B7s2 & Monoculture & MK560317 & MN892340 & FIESC & FIESC \\
\hline B7s4 & Monoculture & MK560318 & MN892330 & FIESC & FIESC \\
\hline B7r2 & Monoculture & MK560273 & MN892300 & FSSC & FSSC \\
\hline B8s1 & Monoculture & MK560333 & MN892346 & F. asiaticum & FGSC \\
\hline B8s2 & Monoculture & MK560274 & MN892299 & FSSC & FSSC \\
\hline B8s4 & Monoculture & MN892354 & MN892308 & FSSC & FSSC \\
\hline B8r1 & Monoculture & MK560276 & MN892298 & FSSC & FSSC \\
\hline B9s1 & Monoculture & MK560334 & MN892345 & F. asiaticum & FGSC \\
\hline B9s2 & Monoculture & MK560277 & MN892282 & FSSC & FSSC \\
\hline B9s4 & Monoculture & MN892353 & MN892329 & FIESC & FIESC \\
\hline B9s5 & Monoculture & MK560330 & MN892350 & F. commune & $\begin{array}{l}\text { Fusarium nisikadoi species } \\
\text { complex, FNSC [42] }\end{array}$ \\
\hline B9r1 & Monoculture & MK560278 & MN892287 & FSSC & FSSC \\
\hline B9r2 & Monoculture & MK560279 & MN892297 & FSSC & FSSC \\
\hline
\end{tabular}

For phylogenetic analysis, the maximum-parsimony (MP) tree was constructed based on both $E F-1 \alpha$ and $R P B 2$ gene sequences of 37 isolates from monoculture, 36 isolates from intercropping, 22 referred isolates and 2 Nectriaceae sp. isolates (NRRL52709 and NRRL52754) as outgroup in Figure 2. The parameters for this tree were followed as 1053 for tree length (TL), 0.762 for consistency index (CI), 0.975 for retention index (RI) and 0.734 for rescale consistency index (RCI), respectively. As shown in Figure 2, all isolates were clearly classified into 10 species or species complex including FIESC, FSSC, F. oxysporum, F. commune, F. fujikuroi, F. proliferatum, F. verticillioides, F. graminearum, F. asiaticum and F. meridionale, which was in agreement with Blastn analysis. The clade bootstrap support values were over 96 for all species and species complex branches. In addition, there was no obvious intraspecies 
genetic differentiation of Fusarium population between monoculture and intercropping. All sequences of EF-1 1 and RPB2 genes have been submitted to NCBI database and GenBank accession numbers were listed in Table 1.

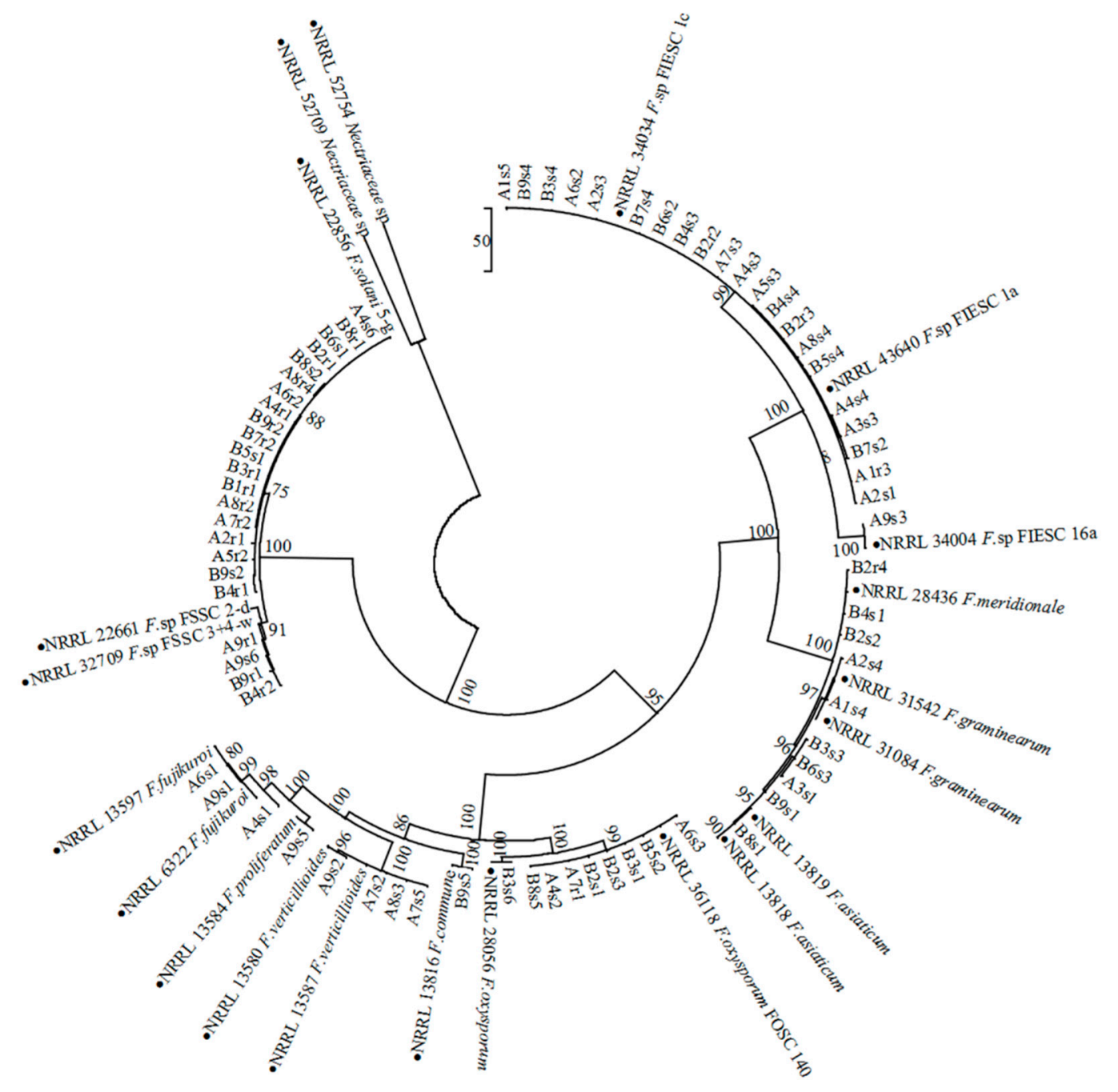

Figure 2. Phylogenetic tree of Fusarium species isolated from soybean monoculture and intercropping based on both $E F-1 \alpha$ and $R P B 2$ gene. The maximum-parsimony (MP) tree was constructed based on both EF-1 $\alpha$ and RPB2 genes with MEGA6.0. Sequences of Nectriaceae sp. (NRRL52709 and NRRL52754) were selected to root the maximum parsimony phylogeny as an outgroup. Numbers at internodes represent MP bootstrap support based on 1000 replicates. Reference sequences of Fusarium isolates from GenBank are indicated by a solid circle.

\subsection{Diversity and Isolation Frequency of Fusarium Species from Monoculture and Intercropping}

As shown in Figure 3, there was a significant difference ( $p=0.038$, Fisher's exact test) in the isolation frequency of Fusarium species, and a higher diversity was observed in intercropping than monoculture at species level. FSSC and FIESC had the higher isolation frequency than other species in both cropping patterns. About $8.33 \%$ of $F$. oxysporum was obtained in intercropping as compared to $16.22 \%$ in soybean monoculture. Fusarium graminearum and F. asiaticum belonging to FGSC covered $8.34 \%$ of those isolates in intercropping, whereas a combination of F. asiaticum and F. meridionale in the same species complex accounted for $18.92 \%$ in monoculture. We also noticed that $F$. verticillioides, $F$. proliferatum and F. fujikuroi in the FFSC were specifically isolated from intercropping pattern with the 
isolation frequency for $11.11 \%, 2.78 \%$ and $8.33 \%$, respectively, while $F$. commune as the specific species exhibited $2.7 \%$ of Fusarium isolates from monoculture. Thus, our results demonstrated that FSSC and FIESC were the dominant species in both cropping systems, but the specifically-isolated FFSC coupled with almost 2-fold lower percentage of both F. oxysporum and species in the FGSC was clearly present in maize/soybean relay strip intercropping rather than soybean monoculture.
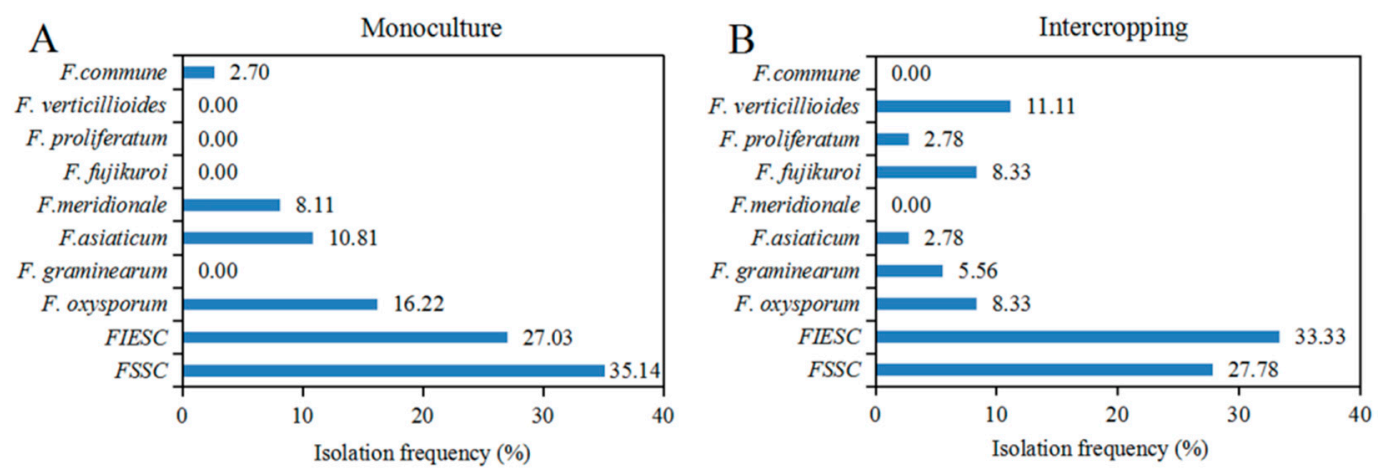

Figure 3. Isolation frequency of Fusarium species isolated from soybean monoculture and intercropping. The values on the bar graph stand for the isolation frequency, which is calculated using the percentage of the isolates of each Fusarium species in total isolates obtained from either monoculture (A) or intercropping (B).

\subsection{Pathogenicity of Fusarium Species from Monoculture and Intercropping}

To test the pathogenicity of Fusarium species identified from soybean monoculture and maize/soybean relay strip intercropping, symptoms of soybean root rot were observed after 15-day inoculation with the representative Fusarium isolates, and the disease severity index (DSI) was calculated according to disease severity caused by Fusarium species. Our results showed that all the representative isolates were able to infect soybean root and caused stunted, brown, rotted taproots and hair roots when compared with the control soybean seedlings (Figure 4). There was obvious different aggressiveness for each Fusarium species, but the representative isolates of each Fusarium species had almost the same DSI in the corresponding cropping pattern. In addition, Fusarium infection resulted in a significant reduction of seedling length and fresh weight of soybean compared with the un-inoculated control soybean in both monoculture (Figure 5A,C) and intercropping (Figure 5C,D).

Among all Fusarium species, F. oxysporum was the most aggressive species with the DSI up to 91.59 in monoculture and 86.63 in intercropping, respectively (Figure 5A,B), and meanwhile it sharply reduced seedling height and fresh weight (Figure 5C-F), affected the development of hair root and resulted in severe rotted taproots of soybean seedlings (Figure 4). Regarding the species belonging to FGSC, F. meridionale (B2s2) and F. asiaticum (B3s3 and B8s1) from monoculture were secondly aggressive to soybean seedlings and caused obvious rotted taproots while F. graminearum (A2s4) and $F$. asiaticum (A3s1) from intercropping had relatively lower DSI. Although both FIESC and FSSC were most frequently isolated in both cropping patterns, they showed different aggressiveness when infected the soybean seedlings. FIESC caused nearly the same disease symptoms in both cropping patterns, whereas FSSC from intercropping was more aggressive than those from monoculture (Figure 5A,B). Interestingly, F. fujikuroi, F. verticillioides and F. proliferatum in the FFSC which were specially identified from intercropping had obvious difference in their aggressiveness after inoculation on soybean with the DSI ranging from 34.92 (A9s5) to 54.50 (A8s3) (Figure 5). Moreover, F. commune (B9s5) as one specific species of monoculture had weak aggressiveness on soybean. In general, our results demonstrated that there were more aggressive Fusarium species with high isolation frequency in monoculture than intercropping, and meanwhile these Fusarium species had also much stronger inhibition effects on seedling length and fresh weight. 

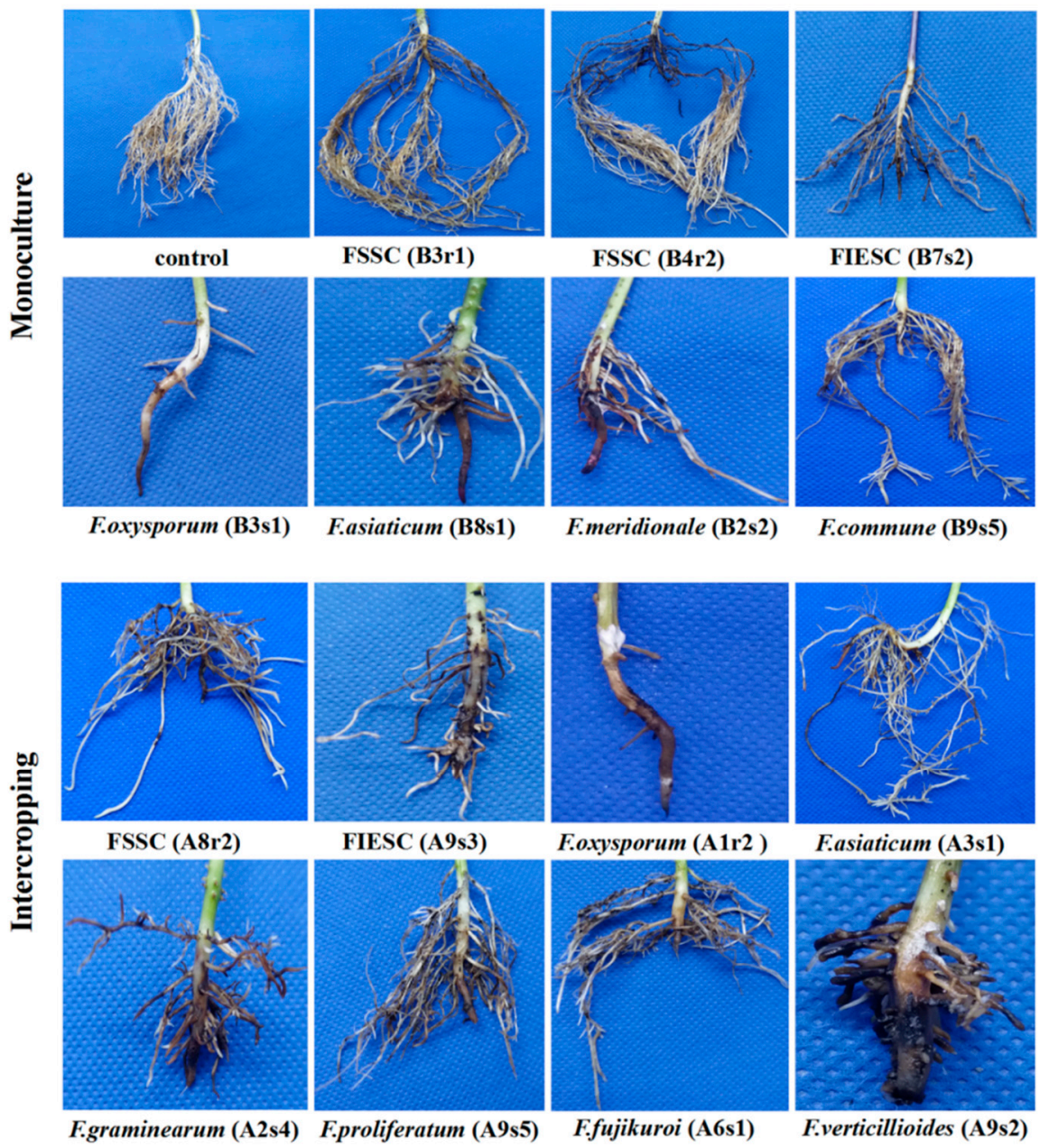

Figure 4. Pathogenicity test of Fusarium species on soybean cultivar Nandou12. Pathogenicity test was performed using sorghum grain infected by the representative Fusarium isolates. FSSC (B3r1, B4r2), FIESC (B7s2), F. oxysporum (B3s1), F. asiaticum (B8s1), F. meridionale (B2s2) and F. commune (B9s5) were isolated from monoculture, while FSSC (A8r2), FIESC (A9s3), F. oxysporum (A1r2), F. asiaticum (A3s1), F. graminearum (A2s4), F. proliferatum (A9s5), F. fujikuroi (A6s1) and F. verticillioides (A8s3) were isolated from intercropping. Control stand for the soybean without Fusarium inoculation. 
A
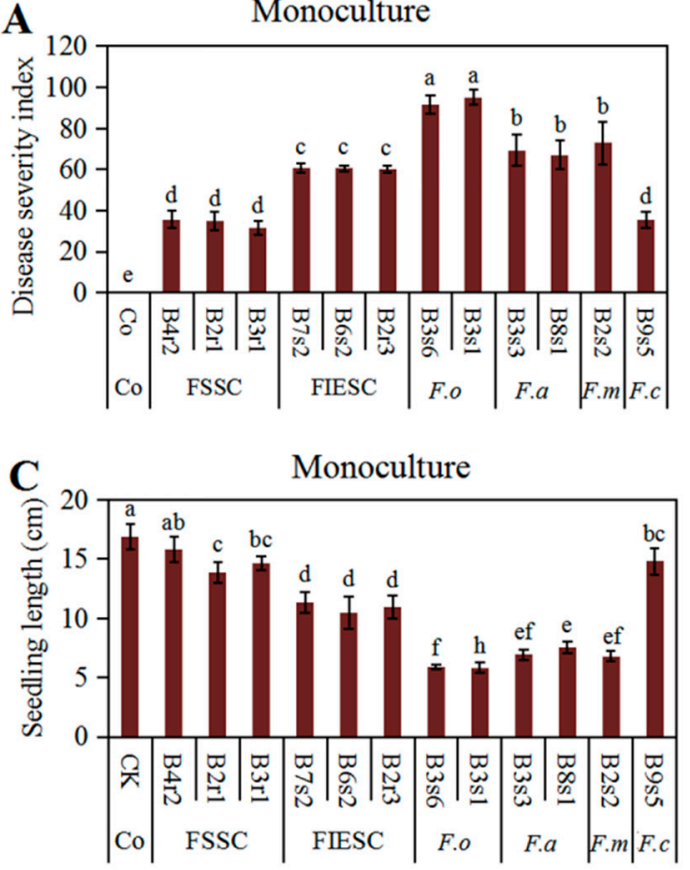

$\mathbf{E}$

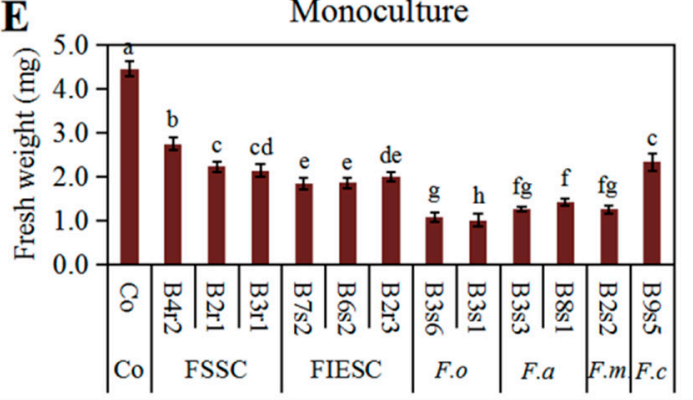

B

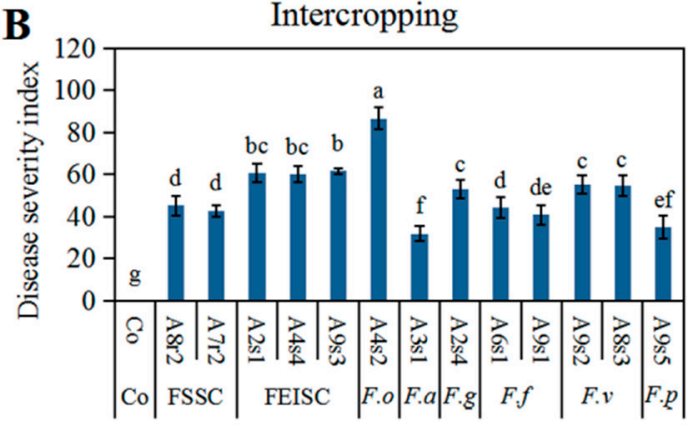

D
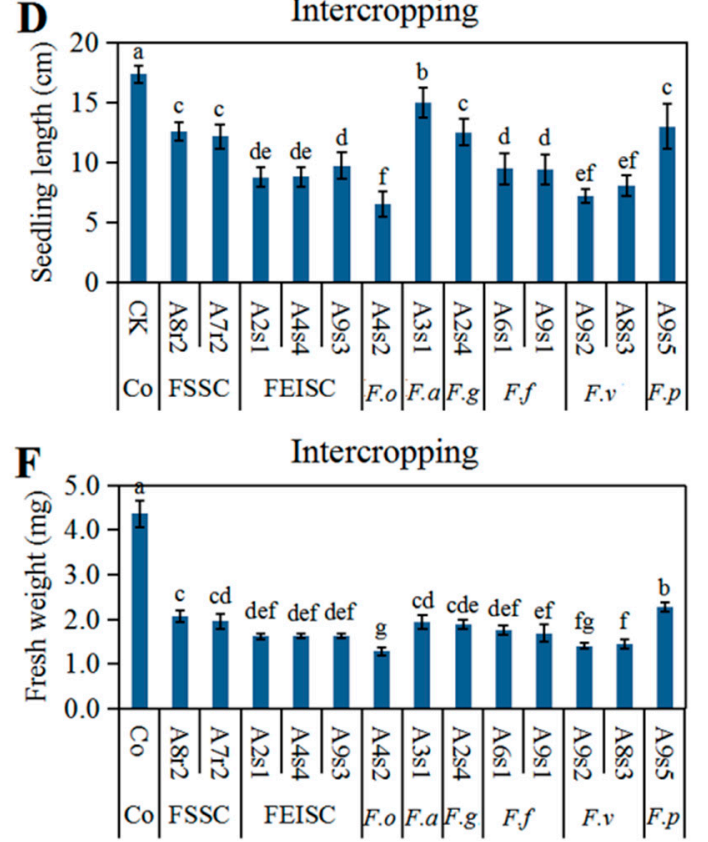

Figure 5. Growth parameters and disease severity index of soybean after inoculation with Fusarium species from monoculture and intercropping. The means of disease severity index, seedling length and fresh weight were obtained from three independent experiments after inoculated with the representative isolates of Fusarium species from monoculture (A, C, E) and intercropping (B, D, F). Co, the seedlings without Fusarium inoculation used as control; FSSC, Fusarium solani species complex; FIESC, Fusarium incarnatum-equiseti species complex; F.o, F. oxysporum; F.a, F. asiaticum; F.m, F.meridionale; F.c, F.commune; F.g, F.graminearum; F.f, F.fujikuroi, F.v, F.verticillioides; F.p, F.proliferatum. Error bars indicate standard error of the mean of three replicates, and each is composed of 18 plants. Bars with different letters are significantly different according to Duncan's test $(p>0.05)$ using SPSS 21 software.

\section{Discussion}

Intercropping has been widely used as an effective agricultural strategy to control soil-borne diseases [17]. Previous studies have proved that intercropping reduces Phytophthora blight of pepper [25], Fusarium wilt of watermelon [15,27], and red crown rot of soybean [14]. Consistently, our studies found that the maize/soybean relay strip intercropping significantly decreased the incidence of soybean root rot by approximately $18.5 \%-36.7 \%$ compared with monoculture (Figure 1). A recent report has revealed that maize plant forms an unavailable non-host "root wall" when intercropped with pepper, thus decreasing the Phytophthora disease of pepper [25]. Under our maize/soybean intercropping pattern, roots of two-row maize plants constitute a physical barrier between two-row soybean strips below the ground (Figure 6B), and this special root space distribution might be very difficult for the dispersion of pathogenic Fusarium species across soybean roots in the rhizosphere [43]. In addition, some reports demonstrated that root secretion from intercropped wheat inhibited spore germination, sporulation 
and growth of the soil-borne F. oxysporum f. sp. niveum causing Fusarium wilt of watermelon [15], and on the other hand it also enhanced the crop resistance through the induction of $P R s$ gene expression and accumulation of phenolic acids in a root-dependent manner [14,15]. Regarding to our intercropping system, maize plants were relay strip intercropped with soybean with the distance of $0.6 \mathrm{~cm}$ that probably is difficult for direct root interaction, but this specific intercropping contributes a lot to a positive interspecific facilitation, improves root nutrition and increases productivity of soybean crop [34,44]. Therefore, we predict that intercropped maize might alter the pathogen establishment and enhance the soybean resistance through formation of root barrier or root interaction.

A

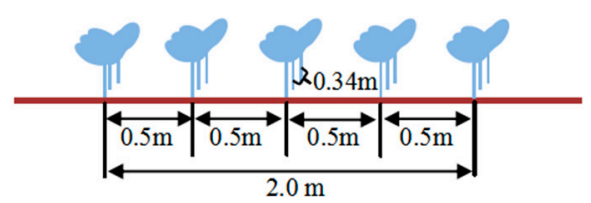

soybean monoculture

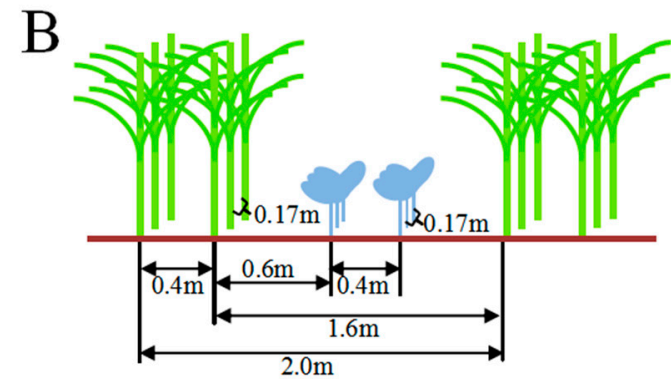

maize/soybean relay strip intercropping

Figure 6. The planting pattern of location field experiments for soybean monoculture and maize/soybean strip intercropping. A. Soybean monoculture; B. Maize/soybean relay strip intercropping.

Previous studies have demonstrated that negative interactions among Fusarium species through competition for space niche and feed resources can effectively affect Fusarium growth and their infection on hosts $[45,46]$. It has showed that $F$. verticillioides has a better growth and a higher spore production than F. graminearum when co-inoculated with maize [45]. Other studies found that as the most important pathogenicity factor of Fusarium species, mycotoxin production was also significantly changed in competing interactions. For example, fumonisins, mainly produced by F. verticillioides, F. proliferatum and F. fujikuroi, were commonly reduced in competing interactions, whereas the DON produced by F. graminearum was increased [47]. In this study, we identified a total of 10 Fusarium species/complex including FIESC, FSSC, F. oxysporum, F. verticillioides, F. fujikuroi, F. proliferatum, F. commune, F. graminearum, F. asiaticum and F. meridionale in location field experiments from two cropping patterns, which is nearly consistent with our previous studies that a co-occurring Fusarium species caused soybean root rot in this region [48]. We also observed a more diverse Fusarium population (8/10) in intercropping than those (6/10) in monoculture, but the DSI over $60.0 \%$ caused by Fusarium species accounted for $25.0 \%(2 / 8)$ in intercropping which was lower than $66.7 \%(4 / 6)$ in monoculture. This indicated that low disease incidence and disease severity index of soybean root rot in intercropping might be associated with a more diverse Fusarium community and their negative interactions, thus resulting in low pathogenic responses to soybean.

To be worthwhile, F. vericillioides, F. fujikuroi and F. proliferatum classified into the FFSC were specifically isolated from intercropping. Actually, they are among important pathogens causing maize ear rot and stalk rot in Sichuan Province and other countries [49-52]. In this study, the co-growth period for maize and soybean lasts more than two months in our maize/soybean relay strip intercropping pattern, and this might provide enough time for the dispersion of Fusarium spores causing maize stalk rot to soybean becoming the inoculums of seedling blight and pod decay of soybean [53]. Furthermore, after harvest, these Fusarium species also can survive saprophytically and accumulate largely on maize and soybean debris, even on or inside field soil, thus may serve as primary inocula for soybean infection in the following year [54]. From this point, there is the possibility for intercropping to increase the risks of root rot through the cyclic infection of some Fusarium species in maize and soybean. Thus, it is very necessary to conduct field studies to further investigate the cross-pathogenicity and cyclic 
infection of these common species, and how they could be managed in an integrated system by effective agricultural practices.

Moreover, we identified three members of FGSC including F. graminearum, F. asiaticum and F. meridionale as the pathogens of soybean root rot in this location field experiment, in particular, F. asiaticum and F. meridionale were firstly reported from soybean in China. It is well-known that F. graminearum is the most destructive pathogens of Fusarium head blight (FHB) $[55,56]$ and maize ear and stalk rot in China and many other countries $[51,52,57,58]$, while F. asiaticum was more frequently isolated with isolation frequency up to $60 \%$ than F. graminearum in Southwest China [56]. Fusarium meridionale is the predominant species on maize in Nepal and Northern Argentina [56] but at quite low frequency in other countries such as South Korea [59]. In our previous studies, F. meridionale was only rarely isolated from wheat and maize in Southwest China including Sichuan and its surrounding areas [56,57], but the factors which influence its distribution are still unknown. In this study, we found that $F$. meridionale was specifically associated with monoculture system, indicating that $F$. meridionale may show host preference on soybean rather than maize and wheat. Some researches suggested that the cropping system was more important in determining the regional prevalence of Fusarium species associated with FHB $[60,61]$. Fusarium graminearum is more frequently associated with maize and wheat rotation when F. asiaticum appear in rice and wheat rotation in Korea [61]. Similarly, multiple intercropping patterns such as rice and maize rotation, wheat/maize and maize/soybean intercropping are widely practiced in Sichuan Province of China [19], and this could put a selective stress on different hosts and help these species of FGSC to shift onto soybean from wheat or maize [56,59]. In addition, we observed that the disease incidence of root rot significantly increased in 2018 as compared to the previous years in two cropping patterns, which was followed by more rainfall days, especially mid of July 2018 during the soybean growth stage (Figure S1). This indicates some certain positive correlation exists between the incidence of Fusarium root rot and rainfall. However, the disease incidence was much higher in monoculture than intercropping, implying that intercropping has much stronger tolerance to unfavorable rainfall. Some studies have demonstrated that unusual climate changes such as severe drought and rainfall damage the natural capacity of soil microbes to suppress soil-borne plant pathogens, contributing to increased disease outbreaks [62].

Currently, the maize/soybean relay strip intercropping has been recognized by Chinese government as one major promotional agricultural cropping pattern because of its competitive advantages on the high yield per unit area and the increase of land equivalent rations (LER) over the traditional maize/soybean intercropping and soybean monoculture [31,35,63]. Our previous studies have demonstrated that the total crop yield of the maize/soybean relay strip intercropping $\left(\mathrm{RI}_{\mathrm{wn}}\right)$ was significantly higher than the traditional maize/soybean intercropping with $\left(\mathrm{RI}_{\mathrm{e}}\right)$ under a normal growing year, and the average LER of the grain yield was 1.79 for $\mathrm{RI}_{\mathrm{wn}}$ and 1.49 for $\mathrm{RI}_{\mathrm{e}}$, respectively [63]. When compared with soybean monoculture, this specific intercropping decreased soybean yield to a small extent based on a 2-year field experiment, but additive relay strip intercropped maize increased the total crop yield in the intercropping system [63]. In this current study, a 7-year continuous intercropping caused $24.8 \%$ lower disease incidence of soybean root rot than monoculture, but the final yield of soybean was not evaluated in both cropping patterns. In the further work, the relationship between disease incidence and the crop yield under maize/soybean relay strip intercropping will be further analyzed to deep understand the underlying mechanism of this intercropping on soybean root rot and Fusarium community.

\section{Materials and Methods}

\subsection{Field Experiments}

The continuous 7-year location-specific field experiments of the maize/soybean rely strip intercropping and soybean monoculture without tillage were conducted at Yucheng District, Yaan City, P. R. China $\left(29^{\circ} 59^{\prime \prime} 3.17^{\prime} \mathrm{N}, 102^{\circ} 59^{\prime \prime} 2.57^{\prime} \mathrm{E}\right)$. The soil in this field was observed as a purple clay texture 
with $\mathrm{pH} 6.71$ and $2.86 \%$ organic matter, and the available $\mathrm{N}, \mathrm{P}$ and $\mathrm{K}$ in the top soil profile $(0-30 \mathrm{~cm})$ of $117 \mathrm{mg} \cdot \mathrm{kg}^{-1}, 31.3 \mathrm{mg} \cdot \mathrm{kg}^{-1}$ and $68.2 \mathrm{mg} \cdot \mathrm{kg}^{-1}$, respectively. The randomized complete block design was used for both intercropping and monoculture with three replicated experimental plots. Each plot was designed for $36 \mathrm{~m}^{2}$ with $6 \mathrm{~m}$ in width and $6 \mathrm{~m}$ in length, comprising 3 strip units in intercropping and 5 rows of soybean in monoculture. For monoculture, the distance of soybean row was $0.5 \mathrm{~m}$ and the hole space was $34 \mathrm{~cm}$ in Figure 6A. The maize/soybean relay strip intercropping was planted as shown in Figure 6B according to Yang et al. [30]. For intercropping, two-row maize was spaced with two-row soybean in $2 \mathrm{~m}$ width as one strip intercropping unit, where the row space was $0.4 \mathrm{~m}$ for maize-maize or soybean-soybean and $0.6 \mathrm{~m}$ for maize-soybean, and the hole space was $17 \mathrm{~cm}$ for both crops. The soybean plants were about 210 in each field of both planting systems. Maize cultivar "Denghai605" and soybean cultivar "Nandou12" were continuously used from 2012 to 2018. Maize was sown in late May and harvested in Mid-August, and soybean was sown in Mid-June and harvested in late October, respectively. All these experiment field were not tilled every year before sowing.

\subsection{Investigation and Sampling of Soybean Root Rot}

Soybean root rot was surveyed from maize/soybean relay strip intercropping and soybean monoculture at $R_{2}$ growth stages according to Killebrew et al. [64] from 2015 to 2018. The disease incidence (DI) and disease severity index (DSI) of root rot were calculated from three replicated experimental plots according to the formula referred to Liu et al. [12]. Total of 18 plants, showing typical symptoms of brown taproots and hair roots, withered and yellowish leaves, were collected from each location field in two planting patterns and were used for pathogen isolation.

\subsection{Isolation of Fusarium Species}

The diseased roots were washed with tap water, cut into small pieces (approximately $1 \mathrm{~mm}^{2}$ ), and surface-sterilized with $75 \%$ ethanol (v/v) for $30 \mathrm{~s}, 1 \% \mathrm{NaOCl}(\mathrm{w} / \mathrm{v})$ for $10 \mathrm{~s}$ and rinsed three times with sterile distilled water. These pieces were placed on Petri dishes containing potato dextrose agar (PDA, $200 \mathrm{~g} \cdot \mathrm{L}^{-1}$ potato, $10 \mathrm{~g} \cdot \mathrm{L}^{-1}$ glucosum anhydricum and $15 \mathrm{~g} \cdot \mathrm{L}^{-1}$ agar), and then incubated at $25{ }^{\circ} \mathrm{C}$ for $7-10$ days in the darkness. All isolates were purified by cutting marginal hyphae and then transferred onto new PDA dishes as test isolates for further analysis according to Chang et al. [48]. The information of isolates was listed in Table 1.

\subsection{PCR Amplification and Phylogenetic Analysis}

For molecular identification, the fungal mycelia were collected from 7-day-old isolates on PDA dishes and then grounded in liquid nitrogen with a disposable pellet pestle. Total genomic DNA of all isolates was extracted using a SP Fungal DNA Kit (Aidlab Biotech, Chengdu, China) according to the manufacturer's protocols. Partial gene sequences of translation elongation factor 1-alpha (EF-1 $\alpha)$ and RNA polymerase beta large subunit II (RPB2) were amplified using the primer pairs EF1/EF2 [38] and RPB2-5f2 /RPB2-7cr [38], respectively. PCR reaction was conducted in a total volume of $25 \mu \mathrm{L}$ containing DNA template $1 \mu \mathrm{L}$, each primer $1 \mu \mathrm{L}(10 \mu \mathrm{M})$ ), Taq PCR Mastermix (Sangon Biotech, Shanghai, China) $12.5 \mu \mathrm{L}$ and DNase free water $9.5 \mu \mathrm{L}$. Amplification conditions were 5 min at $94^{\circ} \mathrm{C}$, followed by 35 cycles of denaturation at $94{ }^{\circ} \mathrm{C}$ for $30 \mathrm{~s}$, annealing at $55^{\circ} \mathrm{C}$ for $30 \mathrm{~s}$, initial extension at $72{ }^{\circ} \mathrm{C}$ for $1 \mathrm{~min}$ and kept at $72{ }^{\circ} \mathrm{C}$ for $10 \mathrm{~min}$. PCR products were detected by $1.5 \%$ agarose gel electrophoresis and then sequenced by an ABI-PRISM3730 automatic sequencer (Applied Biosystems, Foster, CA, USA) in Sangon Biotech Co., Ltd. (Shanghai, China).

For phylogenetic analysis, amplified sequences of $E F-1 \alpha$ and $R P B 2$ gene were blasted on the databases of FUSARIUM-ID (http://isolate.fusariumdb.org/guide.php) and Fusarium MLST (http: //www.wi.knaw.nl/Fusarium/Biolomics.aspx). The referred isolate information of Fusarium species were obtained and listed in Supplementary Materials Table S1. All sequences were edited and aligned with Clustal X 1.83, and characters were weighed equally. A maximum-parsimony (MP) tree was conducted with MEGA 6.0 using the Nearest-Neighbor-Interchange Heuristic method based on both 
EF-1 $\alpha$ and RPB2 sequences. Clade support was inferred from 1000 bootstrap replicates, and alignment gaps were excluded. The tree parameters including tree length (TL), consistency index (CI), retention index (RI) and rescale consistency index (RCI) were also calculated. Novel sequence data were deposited in GenBank and the alignment in TreeBASE (www.treebase.org).

\subsection{Pathogenicity Tests of Fusarium Species}

To complete Koch's postulates, the representative strains from all identified Fusarium species were tested for pathogenicity on the seedling of soybean cultivar Nandou12 through inoculated sorghum grains as described by Chang et al. [48]. Sorghum grains were soaked in distilled water in a $250 \mathrm{~mL}$ flask overnight and autoclaved for $60 \mathrm{~min}$ twice. About 10-15 pieces of mycelium plugs from PDA colonies after 5 days culture were inoculated into sorghum grains and incubated at $25^{\circ} \mathrm{C}$ in the dark for 10 days to obtain the infested sorghum grains. After germination, seeds of cv. Nandou 12 were sowed in plastic pots containing the mixture of autoclaved Pindstrup substrate with infested sorghum grains $(3: 1, w / w)$. Soybean seeds were un-inoculated with sorghum grains as control. Nine plastic pots for each isolate were prepared with two seeds per pot. All inoculated soybeans were incubated in a chamber at $25{ }^{\circ} \mathrm{C}$ with $85 \%$ relative humidity under $12 \mathrm{~h}$ light alternated with $12 \mathrm{~h}$ darkness. This experiment was performed for 3 independent replicates. After 15 days of inoculation, soybean seedlings were removed from the substrate and washed using running tap water. The presence of root rot symptoms and disease severity were evaluated using $0-4$ scale as previously described by Chang et al. [48] with some modifications as follows: $0=$ no symptoms, $1=$ mild symptoms (discoloration but no visible lesions), 2 = obvious lesions (severe discoloration with lateral root reduction), $3=$ severe lesions on the primary and lateral root and diminished plant vigor and $4=$ stem rotten, plant dead. Disease severity index (DSI) was calculated according to the formula as follows. In addition, the seedling height and fresh weights of soybean were recorded.

$$
D S I=\frac{\sum(\text { severityrating } \times \text { seedlingperrating })}{(\text { totalseedlings } \times \text { highestseverityrating })} \times 100
$$

\subsection{Statistic Analysis of Data}

All data were recorded and basically processed using Microsoft office Excel. Mean values of disease incidence (DI) and disease severity index (DSI) in disease field investigation were calculated from three experimental plots of soybean monoculture and maize/soybean relay strip intercropping. In the pathogenicity test, mean values of DSI, seedling height and fresh weight of soybean plants after inoculation with the representative Fusarium isolates were obtained from three independent replicates with 18 seedlings each treatment. The data correlation was conducted by generalized linear model (GLM) with quasipoisson distribution for residuals, and statistical analysis was conducted by Duncan's test with GLM function using IBM SPSS Statistics 21. Significance difference was set at the level of $p=0.05$. The isolation frequency was calculated using the percentage of the isolates of each Fusarium species in total isolates from either monoculture or intercropping, and difference of isolation of Fusarium species in each cropping pattern was analyzed by Fisher's exact test.

\section{Conclusions}

In this study, the effects of maize/soybean relay strip intercropping on soybean root rot, the diversity and pathogenicity of Fusarium species were investigated in a continuous location field experiment when compared with soybean monoculture. We found that this typical intercropping significantly reduced soybean root rot and disease severity as compared to monoculture. Meanwhile, Fusarium species causing soybean root rot in intercropping were more diverse and less aggressive than those in monoculture. Thus, it can be concluded that maize/soybean relay strip intercropping has some positive effects on the reduction of Fusarium root rot probably because of the diversity increase of Fusarium species coupled with their low pathogenicity as a whole. However, the underlying 
mechanisms on the interaction of soybean root and soil microbes in the rhizosphere need to be further explored. In addition, in this study, several Fusarium species identified from soybean are also the pathogens of maize and pre-crop wheat, probably leading to the inoculum accumulation and cross-pathogenicity among crops, and this will increase the risk for the optimum productivity of intercropping. With respect to this, the cross-pathogenicity mechanism of the predominant Fusarium species on intercrops should be elucidated, which will provide a valuable reference for the integrated management of Fusarium root rot in soybean.

Supplementary Materials: The following are available online at http://www.mdpi.com/2076-0817/9/3/211/s1, Figure S1: Investigation of rainfall days at the growth stage of soybean during 2015-2018 in Ya'an City. Table S1: Information of reference isolates and GenBank accession numbers of $R P B 2$ and $E F-1 \alpha$ used for the phylogenetic analysis of Fusarium species causing soybean root rot isolated from soybean monoculture and maize/soybean relay strip intercropping.

Author Contributions: Conceptualization, X.C., L.Y. and W.C.; methodology, L.Y., M.N.; software, L.Y., M.N. and H.Z.; validation, M.N. G.G., M.I.K.; formal analysis, X.C. and L.Y.; investigation, L.Y. and C.S., writing-original draft, X.C., L.Y. and M.N.; writing—review and editing, M.I.K., W.Y. and W.C.; visualization, M.Z. and G.G.; supervision, T.L. and W.C.; project administration, X.C. and T.L.; funding acquisition, X.C. and W.C. All authors have read and agree to the published version of the manuscript.

Funding: This work was supported by National Key Research and Development Program (2018YFD0200500), National Natural Science Foundation of China (31801685), China Agriculture Research System (CARS-03), Central Public-interest Scientific Institution Basal Research Fund (grant number Y2017XM01) and Agricultural Science and Technology Innovation Program (CAAS-ASTIP).

Acknowledgments: We are thankful to Xiaoling Wu for her kindness to provide soybean cultivar used in this study.

Conflicts of Interest: The authors declare no conflict of interest in this work. All financial supports are acknowledged in the contribution. This work does not involve any human participants or animals. All authors have offered the consent to submission.

\section{References}

1. Díaz-Arias, M.M.; Leandro, L.F.; Munkvold, G.P. Aggressiveness of Fusarium species and impact of root infection on growth and yield of soybeans. Phytopathology 2013, 103, 822-832. [CrossRef] [PubMed]

2. Broders, K.D.; Lipps, P.E.; Paul, P.A.; Dorrance, A.E. Evaluation of Fusarium graminearum associated with corn and soybean seed and seedling disease in Ohio. Plant Dis. 2007, 91, 1155-1160. [CrossRef] [PubMed]

3. Díaz-Arias, M.M.; Munkvold, G.P.; Leandro, L.F. First report of Fusarium proliferatum causing root rot on soybean (Glycine max) in the United States. Plant Dis. 2011, 95, 1316. [CrossRef] [PubMed]

4. Díaz Arias, M.M.; Munkvold, G.P.; Ellis, M.L.; Leandro, L.F.S. Distribution and frequency of Fusarium species associated with soybean roots in Iowa. Plant Dis. 2013, 97, 1557-1562. [CrossRef]

5. Barros, G.G.; Alaniz Zanon, M.S.; Chiotta, M.L.; Reynoso, M.M.; Scandiani, M.M.; Chulze, S.N. Pathogenicity of phylogenetic species in the Fusarium graminearum complex on soybean seedlings in Argentina. Eur. J. Plant Pathol. 2014, 138, 215-222. [CrossRef]

6. Chang, K.F.; Hwang, S.F.; Conner, R.L.; Ahmed, H.U.; Zhou, Q.; Turnbull, G.D.; Strelkov, S.E.; McLaren, D.L.; Gossen, B.D. First report of Fusarium proliferatum causing root rot in soybean (Glycine max L.) in Canada. Crop Prot. 2015, 67, 52-58. [CrossRef]

7. Zhou, Q.; Li, N.; Chang, K.F.; Hwang, S.F.; Strelkov, S.E.; Conner, R.L.; McLaren, D.L.; Fu, H.; Harding, M.W.; Turnbull, G.D. Genetic diversity and aggressiveness of Fusarium species isolated from soybean in Alberta, Canada. Crop Prot. 2018, 105, 49-58. [CrossRef]

8. Nelson, B.D.; Hansen, J.M.; Windels, C.E.; Helms, T.C. Reaction of soybean cultivars to isolates of Fusarium solani from the Red River Valley. Plant Dis. 1997, 81, 664-668. [CrossRef]

9. O’Donnell, K.; Sink, S.; Scandiani, M.M.; Luque, A.; Colletto, A.; Biasoli, M.; Lenzi, M.L.; Salas, G.; González, V.; Ploper, L.D.; et al. Soybean sudden death syndrome species diversity within North and South America revealed by multilocus genotyping. Phytopathology 2010, 100, 58-71. [CrossRef]

10. Zhang, J.X.; Xue, A.G.; Cober, E.R.; Morrison, M.J.; Zhang, H.J.; Zhang, S.Z.; Gregorich, E. Prevalence, pathogenicity and cultivar resistance of Fusarium and Rhizoctonia species causing soybean root rot. Can. J. Plant Sci. 2013, 93, 221-236. [CrossRef] 
11. Chang, K.F.; Conner, R.L.; Hwang, S.F.; Ahmed, H.U.; McLaren, D.L.; Gossen, B.D.; Turnbull, G.D. Effects of seed treatments and inoculum density of Fusarium avenaceum and Rhizoctonia solani on seedling blight and root rot of faba bean. Can. J. Plant Sci. 2014, 94, 693-700. [CrossRef]

12. Liu, L.; Kloepper, J.W.; Tuzun, S. Induction of systemic resistance in cucumber against Fusarium wilt by plant growth-promoting Rhizobacteria. Phytopathology 1995, 85, 695-698. [CrossRef]

13. Wang, L.Y.; Xie, Y.S.; Cui, Y.Y.; Xu, J.; He, W.; Chen, H.G.; Guo, J.H. Conjunctively screening of biocontrol agents (BCAs) against fusarium root rot and fusarium head blight caused by Fusarium graminearum. Microbiol. Res. 2015, 177, 34-42. [CrossRef] [PubMed]

14. Gao, X.; Wu, M.; Xu, R.; Wang, X.; Pan, R.; Kim, H.J.; Liao, H. Root interactions in a maize/soybean intercropping system control soybean soil-borne disease, red crown rot. PLoS ONE 2014, 9, e95031. [CrossRef] [PubMed]

15. Lv, H.; Cao, H.; Nawaz, M.A.; Sohail, H.; Huang, Y.; Cheng, F.; Kong, Q.; Bie, Z. Wheat intercropping enhances the resistance of watermelon to Fusarium wilt. Front. Plant Sci. 2018, 9, 696. [CrossRef]

16. Wei, W.; Xu, Y.L.; Zhu, L.; Zhang, S.L.; Li, S. Impact of long-term continuous cropping on the Fusarium population in soybean rhizosphere. Chin. J. Appl. Ecol. 2014, 25, 497-504.

17. Boudreau, M.A. Disease in intercropping systems. Annu. Rev. Phytopathol. 2013, 51, 499-519. [CrossRef]

18. Tanveer, M.; Anjum, S.A.; Hussain, S.; Cerdà, A.; Ashraf, U. Relay cropping as a sustainable approach: Problems and opportunities for sustainable crop production. Environ. Sci. Pollut. Res. 2017, 24, 6973-6988. [CrossRef]

19. Du, J.; Han, T.; Gai, J.; Yong, T.; Sun, X.; Wang, X.; Yang, F.; Liu, J.; Shu, K.; Liu, W.; et al. Maize-soybean strip intercropping: Achieved a balance between high productivity and sustainability. J. Integr. Agric. 2018, 17, 747-754. [CrossRef]

20. Li, L.; Sun, J.; Zhang, F.; Li, X.; Yang, S.; Rengei, Z. Wheat/maize or wheat/soybean strip intercropping I. Yield advantage and interspecifc interactions on nutrients. Field Crop. Res. 2001, 71, 123-137. [CrossRef]

21. Dong, N.; Tang, M.M.; Zhang, W.P.; Bao, X.G.; Wang, Y.; Christie, P.; Li, L. Temporal differentiation of crop growth as one of the drivers of intercropping yield advantage. Sci. Rep. 2018, 8, 3110. [CrossRef] [PubMed]

22. Zhang, F.; Shen, J.; Zhang, J.; Zuo, Y.; Li, L.; Chen, X. Rhizosphere processes and management for improving nutrient use efficiency and crop productivity: Implications for China. Adv. Agron. 2010, 107. [CrossRef]

23. Qin, A.Z.; Huang, G.B.; Chai, Q.; Yu, A.Z.; Huang, P. Grain yield and soil respiratory response to intercropping systems on arid land. Field Crop. Res. 2013, 144. [CrossRef]

24. Mao, L.L.; Zhang, L.Z.; Li, W.Q.; Van der Werf, W.; Sun, J.H.; Spiertz, H.; Li, L. Yield advantage and water saving in maize/pea intercrop. Field Crop. Res. 2012, 138, 11-20. [CrossRef]

25. Yang, M.; Zhang, Y.; Qi, L.; Mei, X.; Liao, J.; Ding, X.; Deng, W.; Fan, L.; He, X.; Vivanco, J.M.; et al. Plant-microbe mechanisms involved in soil-borne disease suppression on a maize and pepper intercropping system. PLoS ONE 2014, 9, e115052. [CrossRef]

26. Ren, L.X.; Su, S.M.; Yang, X.M.; Xu, Y.C.; Huang, Q.W.; Shen, Q.R. Intercropping with aerobic rice suppressed Fusarium wilt in watermelon. Soil Biol. Biochem. 2008, 40, 834-844. [CrossRef]

27. Hao, W.Y.; Ren, L.X.; Ran, W.; Shen, Q.R. Allelopathic effects of root exudates from watermelon and rice plants on Fusarium oxysporum f.sp. niveum. Plant Soil 2010, 336, 485-497. [CrossRef]

28. Gómez-Rodriguez, O.; Zavaleta-Mejı, E.; Gonzalez-Hernandez, V.; LiveraMunoz, M.; Cárdenas-Soriano, E. Allelopathy and microclimatic modification of intercropping with marigold on tomato early blight disease development. Field Crop. Res. 2003, 83, 27-34. [CrossRef]

29. Ratnadass, A.; Fernandes, P.; Avelino, J.; Habib, R. Plant species diversity for sustainable management of crop pests and diseases in agroecosystems: A review. Agron. Sustain. Dev. 2012, 32, 273-303. [CrossRef]

30. Li, L.; Zhang, F.; Li, X.; Peter, C.; Sun, J.; Yang, S.; Tang, C. Interspecific facilitation of nutrient uptake by intercropped maize and faba bean. Nutr. Cycl. Agroecosyst. 2003, 65, 61-71. [CrossRef]

31. Yang, F.; Wang, X.C.; Liao, D.P.; Lu, F.Z.; Gao, R.C.; Liu, W.G.; Yong, T.W.; Wu, X.L.; Du, J.B.; Liu, J.; et al. Yield response to different planting geometries in maize-soybean relay strip intercropping systems. Agron. J. 2015, 107, 296-304. [CrossRef]

32. Liu, X.; Rahman, T.; Song, C.; Su, B.; Yang, F.; Yong, T.; Wu, Y.; Zhang, C.; Yang, W. Changes in light environment, morphology, growth and yield of soybean in maize-soybean intercropping systems. Field Crop. Res. 2017, 200, 38-46. [CrossRef] 
33. Yong, T.W.; Chen, P.; Dong, Q.; Du, Q.; Yang, F.; Wang, X.C.; Liu, W.G.; Yang, W.Y. Optimized nitrogen application methods to improve nitrogen use efficiency and nodule nitrogen fixation in a maize-soybean relay intercropping system. J. Integr. Agric. 2018, 17, 664-676. [CrossRef]

34. Chen, P.; Du, Q.; Liu, X.; Zhou, L.; Hussain, S.; Lei, L.; Song, C.; Wang, X.; Liu, W.; Yang, F.; et al. Effects of reduced nitrogen inputs on crop yield and nitrogen use efficiency in a long-term maize-soybean relay strip intercropping system. PLoS ONE 2017, 12, e0184503. [CrossRef]

35. Su, B.Y.; Liu, X.; Cui, L.; Xiang, B.; Yang, W.Y. Suppression of weeds and increases in food production in higher crop diversity planting arrangements: A case study of relay intercropping. Crop Sci. 2018, 58, 1729-1739. [CrossRef]

36. Tang, Z.Q.; Shang, J.; Zhang, L.; Chen, Y.K.; Chang, X.L.; Du, J.B.; Yong, T.W.; Wu, X.L.; Yu, L.; Zeng, S.H.; et al. Effects of different field configuration modes on population distribution of soybean major insect pests. J. Sichuan Agric. Univ. 2018, 36, 297-308.

37. Aoki, T.; Ward, T.J.; Kistler, C.; O’Donnell, K. Systematics, phylogeny and trichothecene mycotoxin potential of Fusarium Head blight cereal pathogens. JSM Mycotoxins 2012, 62, 91-102. [CrossRef]

38. O'Donnell, K.; Sutton, D.A.; Rinaldi, M.G.; Sarver, B.A.J.; Balajee, S.A.; Schroers, H.J.; Summerbell, R.C.; Robert, V.A.R.; Crous, P.W.; Zhang, N.; et al. Internet-accessible DNA sequence database for identifying Fusarium from human and animal infections. J. Clin. Microbiol. 2010, 48, 3708-3718.

39. O’Donnell, K.; Humber, R.A.; Geiser, D.M.; Kang, S.; Park, B.; Rober, V.A.R.; Crous, P.W.; Johnston, P.R.; Aoki, T.; Rooney, A.P.; et al. Phylogenetic diversity of insecticolous fusaria inferred from multilocus DNA sequence data and their molecular identification via FUSARIUM-ID and Fusarium MLST. Mycologia 2012, 104, 427-445. [CrossRef]

40. O’Donnell, K.; Sutton, D.A.; Fothergill, A.; McCarthy, D.; Rinaldi, M.G.; Brandt, M.E.; Zhang, N.; Geiser, D.M. Molecular phylogenetic diversity, multilocus haplotype nomenclature, and in vitro antifungal resistance within the Fusarium solani species complex. J. Clin. Microbiol. 2008, 46, 2477-2490. [CrossRef]

41. Kvas, M.; Marasas, W.F.O.; Wingfield, B.D.; Wingfield, M.J.; Steekamp, E.T. Diversity and evolution of Fusarium species in the Gibberella fujikuroi complex. Fungal Divers. 2009, 34, 1-21.

42. O' Donnelll, K.; Rooney, A.P.; Proctor, R.H.; Brown, D.W.; McCormick, S.P.; Ward, T.J.; Frandsen, R.J.N.; Lysee, E.; Rehner, S.A.; Aoki, T.; et al. Phylogenetic analyses of RPB1 and RPB2 support a middle Cretaceous origin for a clade comprising all agriculturally and medically important fusaria. Fungal Genet. Biol. 2013, 52, 20-31. [CrossRef] [PubMed]

43. Horberg, H.M. Patterns of splash dispersed conidia of Fusarium poae and Fusarium culmorum. Eur. J. Plant Pathol. 2002, 108, 73-80. [CrossRef]

44. Yang, F.; Liao, D.; Wu, X.; Gao, R.; Fan, Y.; Raza, M.A.; Wang, X.; Yong, T.; Liu, W.; Liu, J.; et al. Effect of aboveground and belowground interactions on the intercrop yields in maize-soybean relay intercropping systems. Field Crop. Res. 2017, 2, 16-23. [CrossRef]

45. Ferrigo, D.; Raiola, A.; Causin, R. Fusarium toxins in cereals: Occurrence, legislation, factors promoting the appearance and their management. Molecules 2016, 21, 627. [CrossRef] [PubMed]

46. Mallon, C.A.; van Elsas, J.D.; Salles, J.F. Microbial invasions: The process, patterns, and mechanisms. Trends Microbiol. 2015, 23, 719-729. [CrossRef]

47. Velluti, A.; Marín, S.; Gonzalez, R.; Ramos, A.J.; Sanchis, V. Fumonisin B1, zearalenone and deoxynivalenol production by Fusarium moniliforme, F. proliferatum and F. graminearum in mixed cultures on irradiated maize kernels. J. Sci. Food Agric. 2001, 81, 88-94. [CrossRef]

48. Chang, X.L.; Dai, H.; Wang, D.P.; Zhou, H.H.; He, W.Q.; Fu, Y.; Ibrahim, F.; Zhou, Y.; Gong, G.S.; Shang, J.; et al. Identification of Fusarium species associated with soybean root rot in Sichuan Province, China. Eur. J. Plant Pathol. 2018, 151, 563-577. [CrossRef]

49. Machado, J.D.C.; Machado, A.Q.; Pozza, E.A.; Machado, C.F.; Zancan, W.L.A. Inoculum potential of Fusarium verticillioides and performance of maize seeds. Trop. Plant Pathol. 2013, 38, 213-217. [CrossRef]

50. Pedrozo, R.; Little, C.R. Fusarium verticillioides inoculum potential influences soybean seed quality. Eur. J. Plant Pathol. 2017, 148, 749-754. [CrossRef]

51. Miedaner, T.; Bolduan, C.; Melchinger, A.E. Aggressiveness and mycotoxin production of eight isolates each of Fusarium graminearum and Fusarium verticillioides for ear rot on susceptible and resistant early maize inbred lines. Eur. J. Plant Pathol. 2010, 127, 113-123. [CrossRef] 
52. Zhou, H.H.; Yan, L.; Wang, D.P.; Yong, T.W.; Gong, G.S.; Shang, J.; Yang, W.Y.; Chang, X.L. Identification of Fusarium species causing maize stalk rot in maize soybean relay intercropping pattern in Sichuan Province. J. Sichuan Agric. Univ. 2018, 36, 598-604.

53. Naeem, M.; Li, H.; Yan, L.; Raza, M.A.; Gong, G.; Chen, H.; Yang, C.; Zhang, M.; Shang, J.; Liu, T.; et al. Characterization and pathogenicity of Fusarium species associated with soybean pods in maize/soybean strip intercropping. Pathogens 2019, 8, 245. [CrossRef]

54. Beyer, M.; Klix, M.B.; Klink, H.; Verreet, J.A. Quantifying the effects of previous crop, tillage, cultivar and triazole fungicides on the deoxynivalenol content of wheat grain-A review. J. Plant Dis. Prot. 2006, 113, 241-246. [CrossRef]

55. Sella, L.; Gazzetti, K.; Castiglioni, C.; Schafer, W.; Favaron, F. Fusarium graminearum possesses virulence factors common to Fusarium head blight of wheat and seedling rot of soybean but differing in their impact on disease severity. Mycology 2014, 104, 1201-1207. [CrossRef]

56. Zhang, H.; der Lee, T.V.; Waalwijk, C.; Chen, W.; Xu, J.; Zhang, Y.; Feng, J. Population analysis of the Fusarium graminearum species complex from wheat in China show a shift to more aggressive isolates. PLoS ONE 2012, 7, e31722. [CrossRef]

57. Sampietro, D.A.; Ficoseco, M.E.; Jimenez, C.M.; Vattuone, M.A.; Catalan, C.A. Trichothecene genotypes and chemotypes in Fusarium graminearum complex strains isolated from maize fields of northwest Argentina. Int. J. Food Microbiol. 2012, 153, 229-233. [CrossRef]

58. Lee, J.; Kim, H.; Jeon, J.J.; Kim, H.S.; Zeller, K.A.; Carter, L.L.; Leslie, J.F.; Lee, Y.W. Population structure of and mycotoxin production by Fusarium graminearum from maize in South Korea. Appl. Environ. Microbiol. 2012, 78, 2161-2167. [CrossRef]

59. Zhang, H.; Brankovics, B.; Luo, W.; Xu, J.; Xu, J.S.; Guo, C.; Guo, J.G.; Jin, S.L.; Chen, W.Q.; Feng, J. Crops are a main driver for species diversity and the toxigenic potential of Fusarium isolates in maize ears in China. World Mycotoxin J. 2016, 9, 701-715. [CrossRef]

60. Lee, J.; Chang, I.Y.; Kim, H.; Yun, S.H.; Leslie, J.F.; Lee, Y.W. Genetic diversity and fitness of Fusarium graminearum populations from rice in Korea. Appl. Environ. Microbiol. 2009, 75, 3289-3295. [CrossRef]

61. Parikh, L.; Kodati, S.; Eskelson, M.J.; Adesemoye, A.O. Identification and pathogenicity of Fusarium spp. in row crops in Nebraska. Crop Prot. 2018, 108, 120-127. [CrossRef]

62. Meisner, A.; de Boer, W. Strategies to maintain natural biocontrol of soil-borne crop diseases during severe drought and rainfall events. Front. Microbiol. 2018, 9, 2279. [CrossRef] [PubMed]

63. Song, C.; Wang, Q.; Zhang, X.; Sarpong, C.K.; Wang, W.; Yong, T.; Wang, X.C.; Wang, Y.; Yang, W. Crop productivity and nutrients recovery in maize-soybean additive relay intercropping systems under subtropical regions in Southwest China. Int. J. Plant Prod. 2020. [CrossRef]

64. Killebrew, J.F.; Roy, K.W.; Lawrence, G.W.; Mclean, K.S.; Hodges, H.H. Greenhouse and field evaluation of Fusarium solani pathogenicity to soybean seedlings. Plant Dis. 1998, 72, 1067-1070. [CrossRef] 